\title{
Development of banana fibers and wood bottom ash modified cement mortars
}

\author{
Banjo Ayobami Akinyemi ${ }^{\mathrm{a}, *}$, Chunping Dai ${ }^{\mathrm{b}}$ \\ a Structures and Environment Unit, Department of Agricultural and Biosystems Engineering, Landmark University, Omuaran, Nigeria \\ ${ }^{\mathrm{b}}$ Department of Wood Science, The University of British Columbia, Canada
}

\section{H I G H L I G H T S}

- Banana fibers and wood bottom ash (WBA) improved the flexural strength.

- Strength development was limited to 10\% WBA optimum content.

- Polymer modification improved the ductility of the composites.

- Polymerisation and pozzolanic chemical reactions occurred at the fibre-matrix interface.

\section{A R T I C L E I N F O}

Article history:

Received 23 October 2019

Received in revised form 21 December 2019

Accepted 2 January 2020

Available online 3 February 2020

\section{Keywords:}

Cement mortar

Wood ashes

Banana fibers

Strength

Agro-wastes

Properties

\begin{abstract}
A B S T R A C T
Many plant wastes have been generated from agriculture for years and as the current global drive towards a green-economy continues, more agro-based wastes will be generated in the future. Some of these wastes are being used presently as a form of renewable energy and result into ashes which are sent to landfills. However, previous studies have shown that ashes could be used as cement replacement while others considered the use of these agricultural wastes from plants as fiber reinforcement in cement applications. In this study, an environment friendly solution was provided to replace cement with wood bottom ashes at 10,15, 20 and $25 \%$ levels and modify the mortars produced with styrene butadiene polymers for improved strength. Also, as a way of providing sustainable path towards utilization of wastes from plant fibers, banana fibers were treated with alkaline solution and used to reinforce the polymer modified cement mortars. The developed cement composites were subjected to mechanical tests, microstructural, elemental, functional group and thermal conductivity analyses. It is realistic to conclude that optimum performance of the composite can be obtained when cement is replaced by up to $10 \%$ of wood bottom ash, $1.5 \%$ of banana fiber content and of $0.3 \%$ of styrene butadiene polymer emulsion The composite developed provided good thermal insulation properties and could be used in some selected cement based applications.
\end{abstract}

(c) 2020 Elsevier Ltd. All rights reserved.

\section{Introduction}

A lot of agricultural residues are produced all over the world with an estimated volume of 1000 million tonnes being generated as wastes. One of the principal contributors to this data is plant residues which account for over $80 \%$ of the total wastes generated [1]. Such wastes are from processing of wood, forest plants and wastes from food crops such as wheat straw, corn cob, bagasse fiber and banana stems to mention a few. Banana plantations exist all over the world being one of the earliest plants grown with over 300 species in existence and it belongs to the Musaceae family [2].

\footnotetext{
* Corresponding author.

E-mail address: bantonbows@gmail.com (B.A. Akinyemi).
}

It has been estimated that over 10 million hectares of it are grown in more than 160 countries in the world resulting in thousands of wastes being generated after harvesting [3]. Sometimes the wastes are left to decompose and it gives out a lot of carbon-dioxide or methane gas. But most times, majority of these wastes end up in dump sites as landfills. These wastes are sources of concern to environmentalists because of their negative effect on ozone layer, underground water, climate change and world economy [4]. Therefore in a bid to utilize them, some of these wastes have found applications in the development of green concrete while others end up being used as a biomass material for energy production.

Green cement and concrete applications involve the use of natural or cellulose based fibers as reinforcement to improve the flexural strength, fracture toughness and ductility of cement 
composites [5,6]. This is usually done in order to develop a sustainable, environment friendly, low cost building material with improved strength characteristics [7]. Some studies have considered the use of wastes from banana plants as fibers in reinforcement of cement composites. One of the earliest studies [8] considered the influence of air curing on banana fibre between 8 and $14 \% \mathrm{w} / \mathrm{w}$ used as cement composite reinforcement. The study reported improved flexural strength and fracture toughness of $20 \mathrm{MPa}$ and $1.74 \mathrm{kJm}^{-2}$ respectively. Other studies such as $[9,10]$ similarly showed improved mechanical properties on inclusion of banana fibers into the composite cement mortars. In the same vein, a comparative study [11] showed that krafted banana fibers was one of the best performers in the evaluation of the compressive strength, modulus of elasticity and rupture, fracture toughness, toughness index and post cracking resistance energy compared to cement composites reinforced with eucalyptus, hemp, jute, $E$. grandis, kenaf, coconut husk and bagasse fibers. It is interesting to note also that among various plants considered in a study involving the determination of chemical constituents of vegetable fibers; banana fibers had the least lignin content which meant that removal of lignin will be easy and little chemical and energy would be required to do so [12]. The presence of lignin, cellulose and hemicellulose in cellulose fibers had been reported to hinder the worldwide adoption of natural fibers as reinforcement in cement composites for large scale construction works [13]. The reason for this is that it develops into chelate complex which hinders the formation of cement hydration products needed for strength development [11]. Therefore it is important to modify natural fiber reinforced cement composites so that it would become a choice building material for major construction applications. This could be done either by modifying the fibers or the cement matrix and possibly a combination of both could be feasible.

Another point raised earlier on the use of agricultural wastes as source of biomass material for energy production, has also led to the emergence of some challenges concerning the disposal of ashes generated thereafter [14]. It is mostly used as landfills thereby constituting an environmental problem. This is usually done without any form of guidelines; these ashes become airborne and could cause respiratory problems for both humans and animals besides the underground water pollution it would cause $[15,16]$. One of the ways through which the problem can be solved is the use of these ashes as cement replacement in various applications. Numerous studies [e.g. [16-19]] had been concluded involving its use as a cementitious binder for aggregates. One of the ways of improving mortar or concrete composites is the use of polymer additives such as styrene-butadiene rubber (SBR) [20]. This would improve the interfacial bond between the aggregates through formation of coherent polymer films and hence enhanced strength properties [21]. Its inclusion would also improve the rate of cement hydration which could counteract the effect of natural fiber addition in the composites. Another way of hastening the formation of hydration is the use of chemicals such as calcium chloride [22,23]. In general, it is evident that limited studies exist on the use of wood bottom ash as cement replacement in a vegetable fiber reinforced cement composites. On the other hand, it is also apparent that few reports exist on banana fiber as choice material for reinforcement of cement composites in a system which the mortar had been modified by a polymer additive.

The goal of this study is to evaluate the engineering characteristics through experimental tests of banana waste fibers used as reinforcement in a modified cement mortar containing wood bottom ash wastes and SBR polymers. In order to do this, Scanning Electron Microscopy (SEM), Energy Dispersive Spectroscopy (EDS) Thermal Conductivity and Fourier Transform Infrared Analysis (FTIR) were used to analyze the microstructural, elemental, heat conductivity and functional group of the samples. Also split tensile and flexural strength tests were conducted on the samples after 7 , 14 and 28 days of water curing.

\section{Materials and methods}

\subsection{Wood bottom ash}

The bottom wood ash (WBA) used came from a biomass boiler (Landmark University cafeteria, Nigeria) at an elevated combustion temperature. Preceding its use, the WBA was oven dried at $90{ }^{\circ} \mathrm{C}$ and thereafter sieved to remove particles with diameter of less than $95 \mu \mathrm{m}$ being the range of the cement particles used Table 1 gives the chemical constituents of the WBA. The sum of $\mathrm{SiO}_{2}, \mathrm{Fe}_{2} \mathrm{O}_{3}$ and $\mathrm{Al}_{2} \mathrm{O}_{3}$ gives $77.88 \%$ which is more than the stipulated $70 \%$ minimum requirement for pozzolans [24]. Therefore, the WBA is a pozzolanic material and could be used as cement replacement.

\subsection{Portland cement}

Type 142.5 grade cement was used as a binder and blended with the WBA pozzolan. The chemical composition is shown in Table 1.

\subsection{Polymer and chemical additives}

The SBR polymer emulsion containing $50 \%$ solid polymer content, $\mathrm{pH}$ of 9.2 , viscosity of 38-159 mPa.s, film forming temperature at $18-23{ }^{\circ} \mathrm{C}$ and average particle size of $0.1 \mu \mathrm{m}$ (supplied by Advanced Concrete Technologies Ltd) was used to modify the cement matrix. The chemical additive used as cement accelerator was calcium chloride at concentration of $3 \%$ weight of cement. Five percent (5\%) concentration of sodium hydroxide was used to treat the surface of the fibres. This alkali treatment would reduce the cellulose and lignin content as well as improve the surface roughness of the fibers for better bonding with the matrix. Equation (1) represents the possible reaction between banana fibers and the alkali used:

Banana fibers $-\mathrm{OH} \rightarrow$ Fibers $-\mathrm{O}-\mathrm{Na}^{+}+\mathrm{H}_{2} \mathrm{O}$

\subsection{Banana fibre}

Wastes from banana plantation within Landmark University was sourced, chopped into $50 \mathrm{~mm}$ length and allowed to dry in the laboratory at $23^{\circ} \mathrm{C}$ for 7 days. It was later hammer milled to reduce the particle sizes and immersed in the diluted sodium hydroxide solution for $2 \mathrm{~h}$. The mixture was decanted and washed in tap water to remove the leached out chemicals and debris. Water rinsing was done five more times to ensure that the banana fibers (BF) were completely free of every trace of the chemicals. Thereafter, the BF was dried in a ventilated oven at $50{ }^{\circ} \mathrm{C}$ for $6 \mathrm{~h}$ before it was allowed to cool in the ambient temperature at $23{ }^{\circ} \mathrm{C}$. The $\mathrm{BF}$ has a width of $4 \mathrm{~mm} ; 13 \mathrm{~mm}$ length and density of $1.30 \mathrm{~g} / \mathrm{cc}$. Results of previous studies has shown that beyond a range of $1-2 \% \mathrm{w} / \mathrm{w}$ fibre content, the properties of natural fibre reinforced cement composites tend to decrease [27,28], therefore a $1.5 \%$ fibre content was used for the design mix as shown in Table 1.

\subsection{Preparation of fibre cement composites}

First, the required quantities of cement and sand in the ratio 1:3 were measured and mixed thoroughly for about $3 \mathrm{~min}$. The cement replacement with WBA was varied at 10, 15, 20 and 25\% (Table 2) and blended together with the aggregates for another $3 \mathrm{~min}$. The control was conditioned at mix U with no WBA and BF for comparison purposes. SBR polymer was also kept constant at $0.3 \%$ of cement based on manufacturer's recommendations. Half of the water to be used for mixing was used to dilute the SBR emulsion for proper mixing with the aggregates and mixing was done manually for 2 min until an homogenous colour and appearance was attained Because of higher volume content of BF used, care was taken during mixing to avoid "balling" by dispersing the fibers uniformly and blending with other aggregates homogenously. Balling is usually caused by increasing volume of fibre content

Table 1

Chemical compositions of cement [25] and wood bottom ash [26].

\begin{tabular}{lll}
\hline Chemical composition & Cement & Wood bottom ash \\
\hline $\mathrm{Al}_{2} \mathrm{O}_{3}$ & 1.25 & 7.52 \\
$\mathrm{SiO}_{2}$ & 18.08 & 65.88 \\
$\mathrm{Fe}_{2} \mathrm{O}_{3}$ & 10.5 & 4.48 \\
$\mathrm{CaO}$ & 51.67 & 11.10 \\
$\mathrm{MgO}$ & 1.45 & 2.53 \\
$\mathrm{~K}_{2} \mathrm{O}$ & - & 5.87 \\
$\mathrm{SO}_{3}$ & 1.40 & 1.37 \\
$\mathrm{Na}_{2} \mathrm{O}$ & - & 0.42 \\
$\mathrm{LOI}$ & 3.27 & 15 \\
\hline
\end{tabular}


Table 2

Experimental formulation design.

\begin{tabular}{|c|c|c|c|c|c|c|}
\hline \multirow[t]{2}{*}{ Components } & \multirow[b]{2}{*}{$\mathrm{U}$} & \multicolumn{5}{|c|}{ Mix design } \\
\hline & & $\mathrm{K}$ & V & $\mathrm{W}$ & $\mathrm{X}$ & $\mathrm{Y}$ \\
\hline Cement (\%) & 24.70 & 24.55 & 22.05 & 20.80 & 19.55 & 18.30 \\
\hline Sand (\%) & 75 & 73.65 & 66.15 & 62.40 & 58.65 & 54.90 \\
\hline Treated fibers (\%) & - & 1.5 & 1.5 & 1.5 & 1.5 & 1.5 \\
\hline SBR (\%) & 0.3 & 0.3 & 0.3 & 0.3 & 0.3 & 0.3 \\
\hline WBA (\%) & - & - & 10 & 15 & 20 & 25 \\
\hline *Water/cement & 0.35 & 0.40 & 0.40 & 0.42 & $0.46^{\mathrm{d}}$ & 0.49 \\
\hline
\end{tabular}

*Water/cement was expressed in ratio, others were expressed in \%.

which could affect the workability and stiffness of the cement matrix hence reduction in strength if care is not taken. Thereafter the remaining water was blended together with other constituents for another 3 min until slurry was formed. Additional water was added when necessary until the desired slurry consistency was attained. The mortar was cast in $200 \mathrm{~mm}$ (length) $\times 50 \mathrm{~mm}$ (breadth) $\times 5 \mathrm{~mm}$ (thickness) flexural moulds and $50 \mathrm{~mm}$ (diameter) $\times 150 \mathrm{~mm}$ (length) split tensile moulds respectively. A total of 120 mortar specimens were produced and allowed to set in the moulds. The samples were demoulded after $24 \mathrm{~h}$ and cured in a water tank at a temperature of $22^{\circ} \mathrm{C}$ for 7,14 and 28 days. For the various tests conducted, 8 replicates from each batch were tested for each curing period. The materials used and the flow process are shown in Figs. 1 and 2.

\subsection{Test programme}

\subsubsection{Mechanical engineering tests}

Modulus of rupture (MOR) and modulus of elasticity (MOE) were performed according to ASTM standard [29] using a Testometric universal testing machine at a loading rate of $1.5 \mathrm{~mm} / \mathrm{min}$ until failure occurred. 8 replicates were tested for each level of mix design. Split tensile tests were conducted according to BS EN standard [30] at a loading rate of $1.2 \mathrm{kN} / \mathrm{s} .8$ cylindrical samples were similarly tested at each curing age for repeatability sake and the mean was presented in this study.

\subsubsection{Instrumental analyses}

Scanning electron microscope (SEM) and energy dispersive spectroscopy (EDS) were performed using Jeol-7600F equipment for micrograph observation as well as elemental compositions of the fractured samples. For the thermal performance, thermal conductivity was determined with an Hot Disk Thermal Constants Analyser (model no. TC48AC) using transitory plane source principle [31]. Four samples were analyzed; these were samples V, W, X and Y. The sensor was placed between two samples of the same mix content and proper contact needed for thermal tests were ensured in order to eliminate voids and cracks on the surface of the specimens. This test was performed under laboratory conditions of $23^{\circ} \mathrm{C}$ and $97 \%$ relative humidity. Fourier transform infrared analysis (FTIR) was conducted to determine the functional groups of the cellulose fiber cement composites using Shimadzu FTIR8400 spectrophotometer.

\section{Results and discussion}

\subsection{Mechanical properties}

\subsubsection{Modulus of rupture (MOR)}

Fig. 3 showed the effect of varied wood bottom ash contents on banana fiber reinforced-polymer modified mortar. For 7 days, a

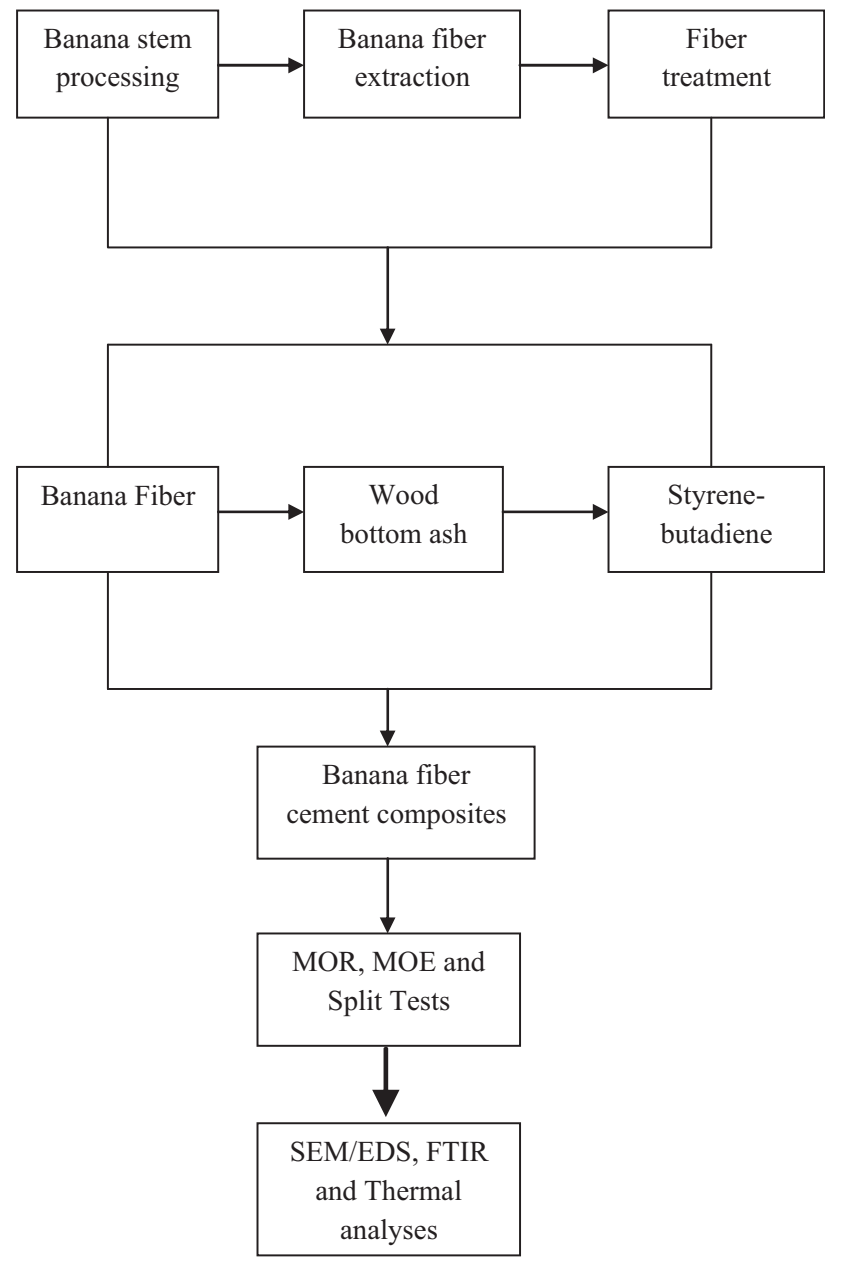

Fig. 2. Flow chart of cement composite production.

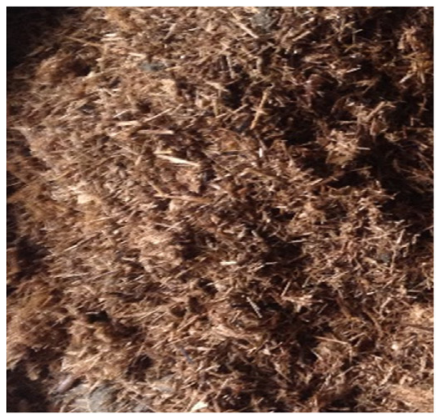

(a) Treated banana fiber

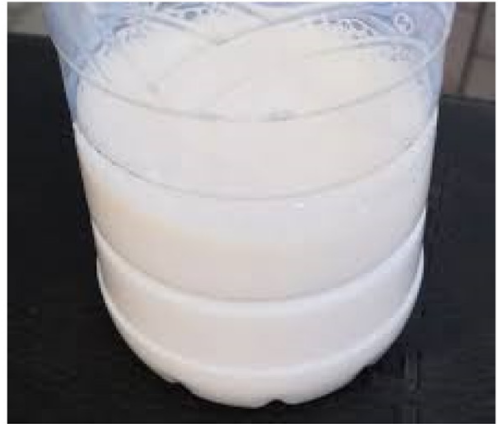

(b) SBR Polymer

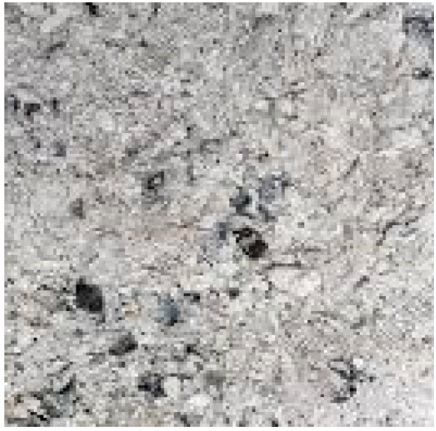

(c) Wood bottom ash

Fig. 1. Constituent materials. 
reduction of $45.4 \%$ was noticed for reference material $U$ (no WBA and $\mathrm{BF}$ ) when compared with mix V (10\% WBA + 1.5\% BF + 0.3\% SBR). Others are $15.9,11.6$ and $8.5 \%$ reduction in strength respectively for mix $U$ in comparison with $\mathrm{W}(15 \% \mathrm{WBA}+1.5 \% \mathrm{BF}+0.3 \% \mathrm{SBR}), \mathrm{X}$ $(20 \% \mathrm{WBA}+1.5 \% \mathrm{BF}+0.3 \% \mathrm{SBR})$ and $\mathrm{Y}(25 \% \mathrm{WBA}+1.5 \% \mathrm{BF}+0.3 \%$ $\mathrm{SBR})$. This showed that the BF and WBA content had positive influence on the flexural strength as the curing days progressed when compared with control sample. However, a look at the effect of varied WBA contents on MOR at constant BF inclusion showed that after the optimum strength was attained at $10 \%$ inclusion in mix $V$, a gradual decrease in strength occurred in the fibre reinforced cement composites. An increase from $10 \%$ to $15 \%$ WBA resulted in $26 \%$ reduction, $15 \%$ to $20 \%$ dosage increase showed $2.9 \%$ decrease and from $20 \%$ to $25 \%$ increase in WBA content, a $2.9 \%$ decrease in MOR was obtained after 7 days curing. Similar reduction in strength on inclusion of higher dosages of WBA was noted across the remaining curing duration. This observation is in line with the report of an investigation conducted by [32] on the engineering properties of fly ash modified fiber reinforced concrete with the $10 \%$ dosage of the flyash producing the highest flexural and compressive strength performance after curing the reinforced concrete for 28 days. It was stated in the study that higher dosages of the flyash reduced the mechanical properties of the cement composites. A reason adjudged for this in a recent research on mechanical performance of flyash and glass fibers reinforced concrete conducted by [33] showed that as the dosages of agricultural waste ashes are increased in a cement matrix, the number of unreacted particles in them would also increase once the optimum strength at a specified ash content has been attained. Hence, the improvement of the modulus of rupture strength would be reduced because the hydrated products could no longer hold the BF firmly any longer again. To corroborate this assertion, Silva et al [34] also reported that at higher dosage of ash content beyond $20 \%$ cement replacement, the ashes caused a delay on the pozzolanic effect it should have had on the strength development because it acted more as a filler than as a binder in the cement matrix. The use of BF improved the modulus of rupture after the loss of strength due to inclusion of WBA. Mix K $(1.5 \%$ $\mathrm{BF}+0.3 \% \mathrm{SBR}$ ) had $13.14,5$ and $3.64 \%$ improved flexural strength more than the reference mix after the respective curing ages. On introduction of fibers to cement composites after a noticeable reduction in strength on blending with ashes, an increased flexural performance was similarly reported by [35]. It was observed that remarkable improvement in flexural strength of $14 \%$ was observed for $1 \%$ steel fiber reinforcement when compared with control mix with fly ash only.

\subsubsection{Modulus of elasticity}

Similar situations as seen in MOR were observed during the modulus of elasticity test results shown in Fig. 4. It is clearly evident that at $10 \%$ WBA content and BF reinforcement in Mix V,

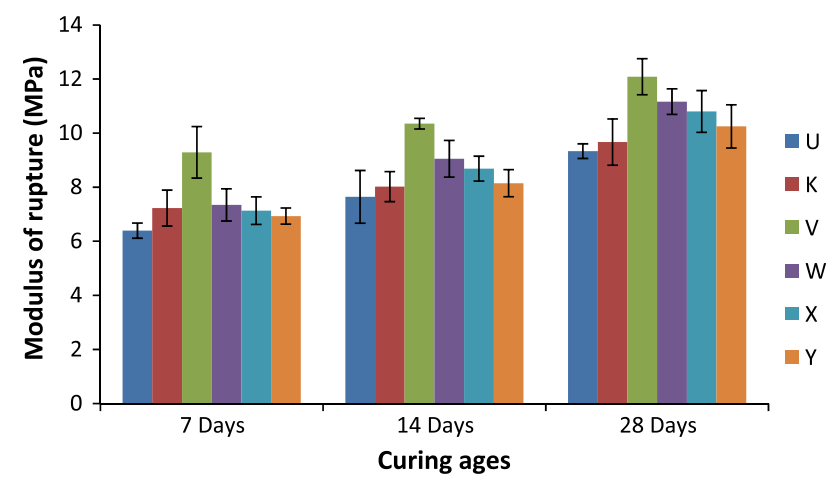

Fig. 3. Modulus of rupture of cement composites.

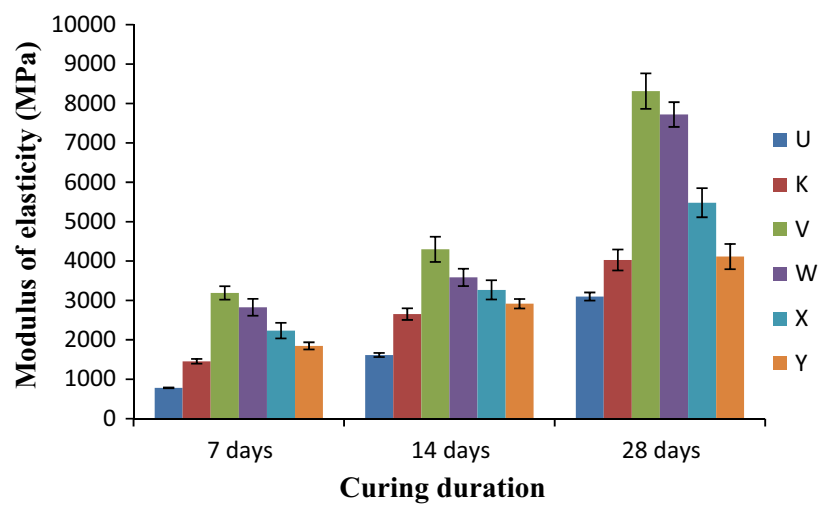

Fig. 4. Modulus of elasticity of cement composites.

the optimum strength was achieved. However, for the given BF content at varied proportions of WBA, the modulus of elasticity reduced. The presence of $\mathrm{BF}$ in the matrix improved the ductility and toughness of the fiber reinforced composites due to compact contact with the modified cement mortar. Therefore, the BF was able to resist fiber pull out by arresting the micro-cracks induced by the applied load. Previous study [36] also highlighted the same situation that at constant pond ash content and increasing fiber content, the flexural strength of a fiber reinforced concrete was improved. It was also stated that for every increase in the dosage of the pond ash at a given value of fiber, the flexural strength reduced significantly. The presence of the SBR emulsion polymer could possibly also influence the ductility improvement of the cement matrix through the development of multiple dimensioned network of polymer within the cured cement composites [37]. It has also been reported that polymer modification of cementitious matrices helps in controlling cracks due to filling of voids that could develop during the hydration process by its films, thereby decreasing the size of pores and hence an improved strength would take place [38].

\subsubsection{Split tensile strength}

There was a marked improvement on inclusion of $\mathrm{BF}$ into the mix at $\mathrm{K}$ with 33, 19 and $20 \%$ higher tensile resistance than the reference mix after the curing ages (Fig. 5). Split tensile strength reduced appreciably with increasing WBA content at the given $\mathrm{BF}$ content. This is because for any given proportion of WBA, the ash being a pozzolanic substance could not improve the tensile strength. Rather, it contributes to the formation of flocs which are more capable of resisting compressive strength than split tensile strength [36]. Hence, for every increase in the ash content, flocculation within the composite increases, therefore the capability of

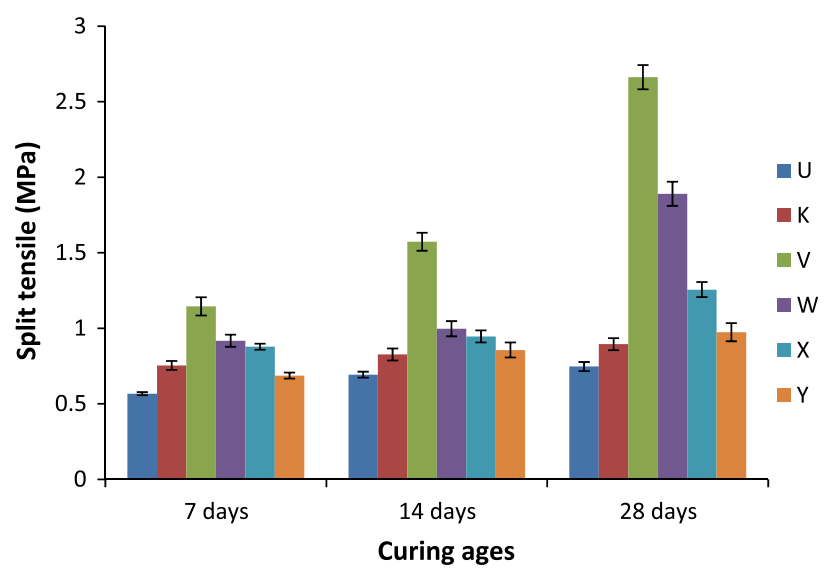

Fig. 5. Split tensile strength of fiber reinforced cement composites. 
the system to oppose tensile forces diminishes. Another study by [39] on the split tensile strength of wood waste ash used as cement replacement showed similar observations with this current study. It was reported in the investigation that the splitting tensile strength of the concrete mixes reduced as the percentage of the wood waste ash was increased after 7 and 28 days curing. Another possible explanation for this decline in split tensile strength is that, as more WBA was added, many unreacted ash particles were developed which acted more as a filler which has poor resistance to tensile forces than compressive forces.

\subsection{Microstructural, elemental and functional group analyses}

\subsubsection{Microstructural analysis}

SEM of mix V (Fig. 6(a)) showed that the interface is well compacted with occurrence of cement hydrate products and polymer films fully bonded together. The banana fibers are well encapsulated with calcium silicate hydrates (C-S-H) and polymer films which helped in bridging the gap between the fibre and cement matrix. After the alkaline treatment, the surface of the BF appears hollow and rough depicting the reduction of cellulose and lignin from its surface. The roughened surface was thereafter filled the abundant cement hydrate products which ultimately helped to attain the optimum strength when compared with others. There was no occurrence of unreacted ash particles on the micrograph with few voids appearing on the interface as well. The SBR polymer films improved the compact network of the interfacial transition zone of the BF-matrix. The EDS was taken at the selected regions of the different micrographs. For mix W (Fig. 6(b)), the interfacial outlook is less well compact with limited appearance of whitish and round unreacted particles of the ashes on the surface. However, its presence which was responsible for the lower strength in comparison with mix $\mathrm{V}$ was well compensated by the commingling of the hydration products from WBA-cement pozzolanic hydration products and the polymer films from SBR. The interaction by these materials led to improved bonding and formation of adequate strength capable of resisting the applied loads during the mechanical tests. Fig. 7(a; b) depict the micrographs of mixes $\mathrm{X}$ and $\mathrm{Y}$. There were more presence of voids in Fig. $7 \mathrm{~b}$ than Fig. 7a. Also, mix $X$ has moderate numbers of the whitish and round unreacted WBA than mix Y. The numerous occurrences of these ashes were responsible for the low performance they both recorded in the mechanical tests.

\subsubsection{Elemental analysis}

Energy dispersive spectroscopy (EDS) analyses were performed by selecting the regions marked as $\mathrm{A}, \mathrm{B}, \mathrm{C}$ and $\mathrm{D}$ on the respective micrographs. The spectra images gotten were used to create Table 3 for mixes V, W, X and Y. All the samples consisted of silicon, carbon, calcium, oxygen, and iron with traces of magnesium. It is however clear that sodium was not discovered in any of the samples, this attests to the efficacy of the alkaline treatment of BF in removing them. It has been reported also that the $\mathrm{C} / \mathrm{O}$ ratio of cellulose, pectin and hemicellulose is 1.21 [40], it was on the other hand noticed that all the $\mathrm{C} / \mathrm{O}$ ratios were significantly below this and it confirmed the earlier fact that the cellulose, lignin and hemicellulose of the BF have been reduced greatly so this could have contributed to the improved strength of the cement composites. It has also been reported that higher concentration of calcium is responsible for low performance of vegetable fiber cement composites $[41,42]$. Its proximity to the surface of the fibers leads to the development of more calcium ions than silicon because of the dissolving natural fibre-water soluble compounds leading to the formation of calcium salts at high $\mathrm{pH}$ levels between 11 and 12 [43]. A similar statement was made by Fedorov and Mestnikov [44] who stated that higher values of calcium ions are responsible for the formation of crystallization points at the interface between natural fibers and cement mortars and followed up by the creation of $\mathrm{Ca}(\mathrm{OH})_{2}$ crystals in the matrix. As it can be noticed, the least value of calcium was obtained at mix $V$ which could be responsible for improvement in the mechanical strength more than the others. The $\mathrm{Ca} / \mathrm{Si}$ ratios for the mixes are $\mathrm{V}=4.42, \mathrm{~W}=5.94, \mathrm{X}=5.63$, $\mathrm{Y}=4.81$ respectively. This was also responsible for the formation of calcium silicate hydrate (C-S-H) at the surface of the composite. The improved performance of mix $\mathrm{V}$ over the others is because the $\mathrm{C}-\mathrm{S}-\mathrm{H}$ content increased with decreasing $\mathrm{Ca} / \mathrm{Si}$ ratio and therefore the proportion of the C-S-H gel is highest at this lowest level of $\mathrm{Ca} / \mathrm{SiO}$ ratio [45]. It is also a product of pozzolanic reaction between WBA (65.88\% $\mathrm{SiO}_{2}$ composition) and cement $(18.08 \%$ $\mathrm{SiO}_{2}$ composition). A larger amount of $\mathrm{SiO}_{2}$ has been reported to be the cause of development of substantial quantities of CSH on the surface of the fibre which consumed the $\mathrm{CH}$ and reduced the

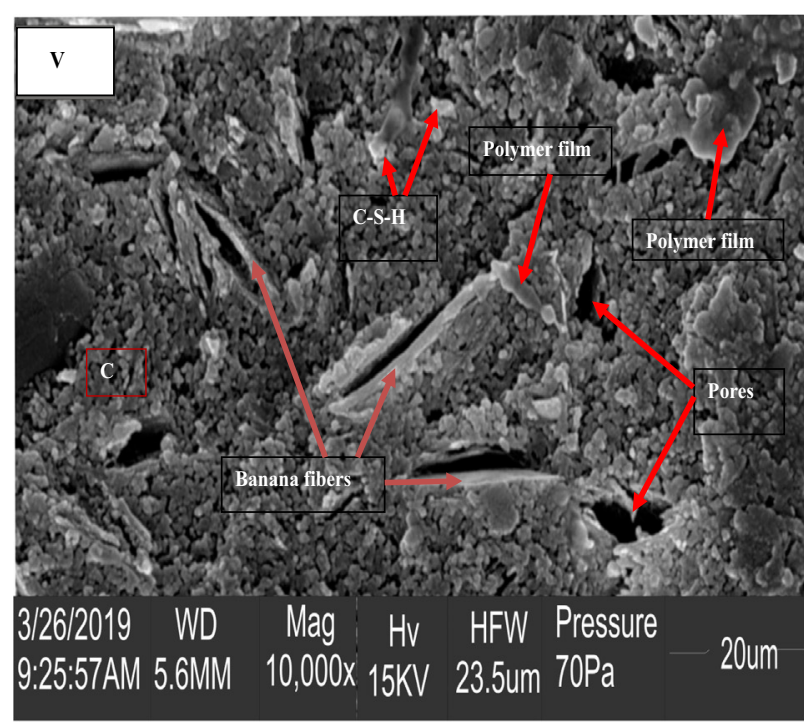

(a) SEM of mix V $(10 \% \mathrm{WBA}+\mathrm{BF}+\mathrm{SBR})$

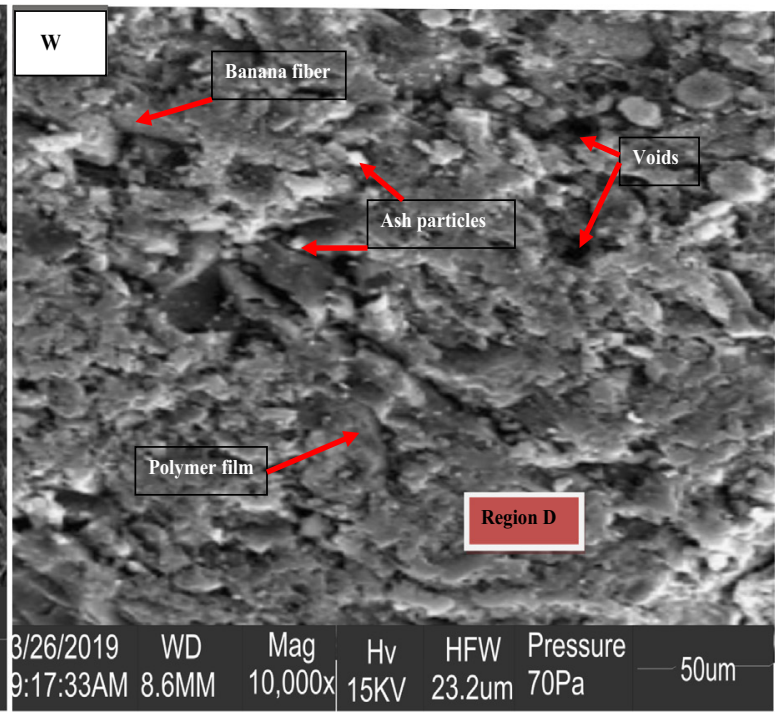

(b) SEM of mix W $(15 \% \mathrm{WBA}+\mathrm{BF}+\mathrm{SBR})$

Fig. 6. Micrographs of mixes $\mathrm{V}$ and $\mathrm{W}$. 


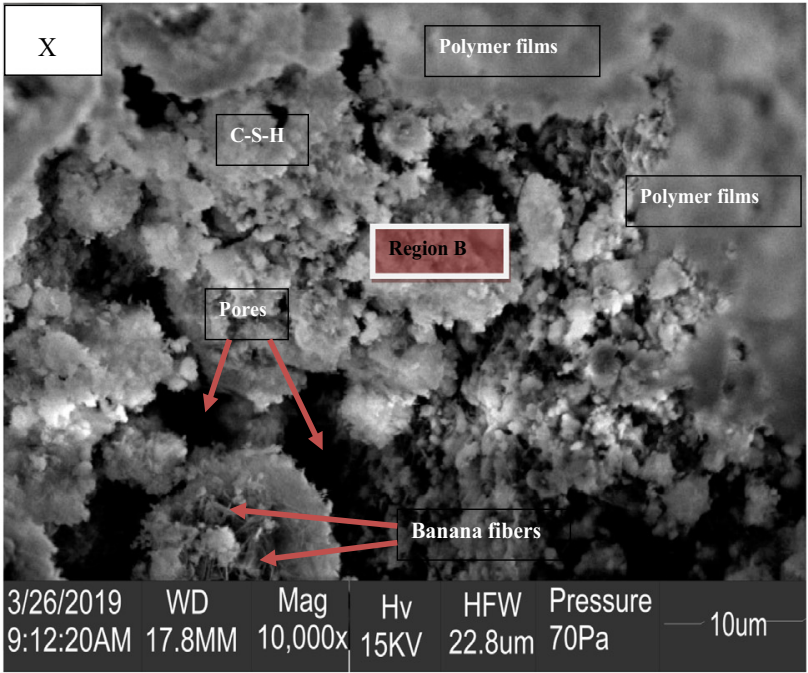

(a) SEM of mix X $(20 \% \mathrm{WBA}+\mathrm{BF}+\mathrm{SBR})$

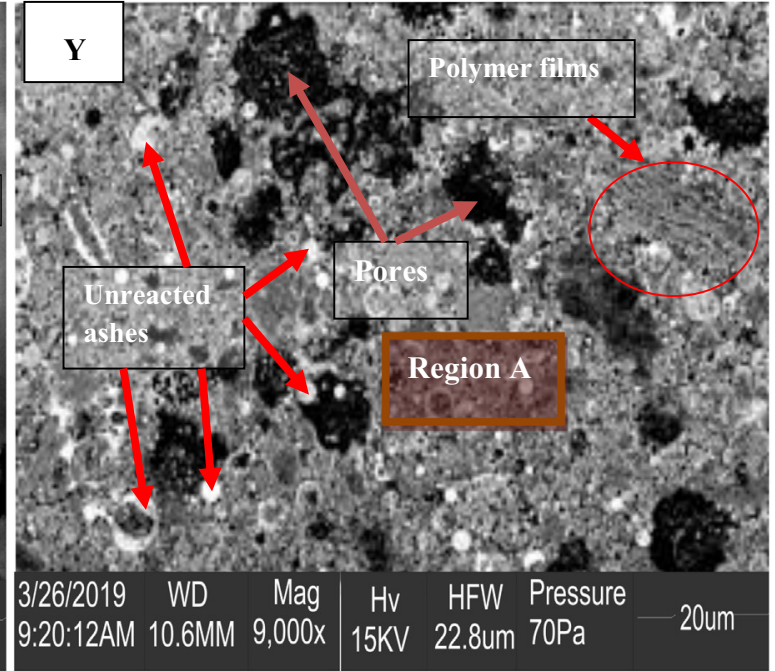

(b) SEM of mix W (25\%WBA+BF+SBR)

Fig. 7. Micrographs of mixes $\mathrm{X}$ and $\mathrm{Y}$.

Table 3

Elemental composition of cement composites.

\begin{tabular}{lllll}
\hline Spectra label & $\mathrm{V}(\%)$ & $\mathrm{W}(\%)$ & $\mathrm{X}(\%)$ & $\mathrm{Y}(\%)$ \\
\hline $\mathrm{C}$ & 7.25 & 3.20 & 6.10 & 5.15 \\
$\mathrm{O}$ & 30.20 & 30.20 & 30.40 & 37.20 \\
$\mathrm{Fe}$ & 4.25 & 6.30 & 6.35 & 6.20 \\
$\mathrm{Ca}$ & 46.50 & 50.50 & 47.60 & 41.60 \\
$\mathrm{Si}$ & 10.50 & 8.50 & 8.45 & 8.65 \\
$\mathrm{Mg}$ & 1.40 & 1.10 & 1.20 & 1.30 \\
\hline
\end{tabular}

pores developed in the interfacial zone between the fibre-matrix [46]. The SBR polymer emulsion also improved the fiberpozzolan bonding situations, aided the pozzolanic chemical reactions and boosted the process of cement hydration [47].

\subsubsection{Functional group analysis}

FTIR analysis (Fig. 8) was conducted and the spectra wavenumbers of importance in this study have been identified in Table 4 . For the different compositions, the bands ranging from 3437.26 to $3450.77 \mathrm{~cm}^{-1}$ is denoted for stretched $\mathrm{OH}^{-}$group with a pronounced increase in the intensity of the particular band for Y when compared with others. This is indicative of the effective chemical reactions and stability among the $B F, W B A$ and the SBR polymer in the mixes V, W and X more than mix Y [48]. Basically, there were little variations among the bands of the four spectras considered because the amount of coincidences among them is high. Nevertheless, some distinctions could be spotted as regards the absence of bands $694.40 \mathrm{~cm}^{-1}$ at mixes $\mathrm{V}, \mathrm{W}$ and $\mathrm{Y}$ and $2044.61 \mathrm{~cm}^{-1}$ at mixes $\mathrm{V}, \mathrm{W}$ and $\mathrm{X}$ respectively. These are representatives of losses of the $\mathrm{C}-\mathrm{OH}$ bending and $\mathrm{C}-\mathrm{H}$ vibration bands with low intensities because of the alkaline environment of the cement hydration products. The FTIR analysis has shown that despite the loss of few functional groups, the modification of the cement mortar with WBA and SBR polymers as well as fibre reinforcement were generally responsible for the improved performance of the composites. This improvement has been explained by the combined actions from the polymerisation and pozzolanic chemical reactions at the fibrematrix interface as clearly seen from the SEM and EDS analyses.

\subsection{Thermal conductivity}

The presence of natural fibers in cement composites has been stated to be a major factor for low thermal conductivity (TC) because it causes the disruption of the mineral structure of the cement mortars. This is also coupled with the creation of voids and pores within the composite thereby reducing the heat transfer potential [49]. The thermal conductivity (Table 5) showed that the least value belongs to mix $\mathrm{V}(0.620 \mathrm{~W} / \mathrm{mK})$ with the least cement replacement (10\% WBA) while the highest TC was obtained from composition with highest cement replacement (25\% WBA) at $0.628 \mathrm{~W} / \mathrm{mK}$. This meant that the higher the cement proportion, the higher the TC of the composite material. A similar circumstance was encountered in an investigation conducted by Demirboğa [50] on replacing cement with silica fume, fly ash and blast furnace slag. The observation from the study was that lower TC values were obtained on increasing the percentage of the ashes. Reduction in density of the cement mortar led to low heat transfer within the molecules of the composites. This has been attributed to the amorphous nature of the ashes used and the mineral constituents of the cement mortar [51]. Generally, the composite materials could be classified as good insulators because of the lower thermal conductivity results when compared with that of concrete $(1.91 \mathrm{~W} / \mathrm{mK})$ [52].

\section{Summary and conclusions}

In this experiment, the effects of reinforcing wood bottom ash and styrene butadiene rubber polymer modified cement mortars with banana fiber wastes have been studied. The modulus of elasticity (MOE), modulus of rupture (MOR) and split tensile strength were evaluated. Also, SEM, EDS, FTIR and thermal conductivity analyses were performed on the cement composites. Inclusion of $\mathrm{BF}, \mathrm{WBA}$ and SBR polymer into the cement matrix led to improved MOR. However, the WBA cementitious ashes had no direct effect on the resistance to tensile forces therefore as the proportion of the ashes were increased, a reduction in both the MOR and MOE values were noticed at the given fiber content. 19-33\% improvement in split tensile strength was noticed on inclusion of BF alone but split strength reduced appreciably with increasing WBA content at the given BF content for other mixes. However, a significant positive correlation occurs between the split tensile strength and $\mathrm{BF}+\mathrm{SBR}$ additives. SEM analysis showed that the SBR polymer enhanced the interface of the fiber-matrix by filling the voids with polymer films which created a dense microstructure. The mechanism responsible for this could be called pozzo-lymer which is 

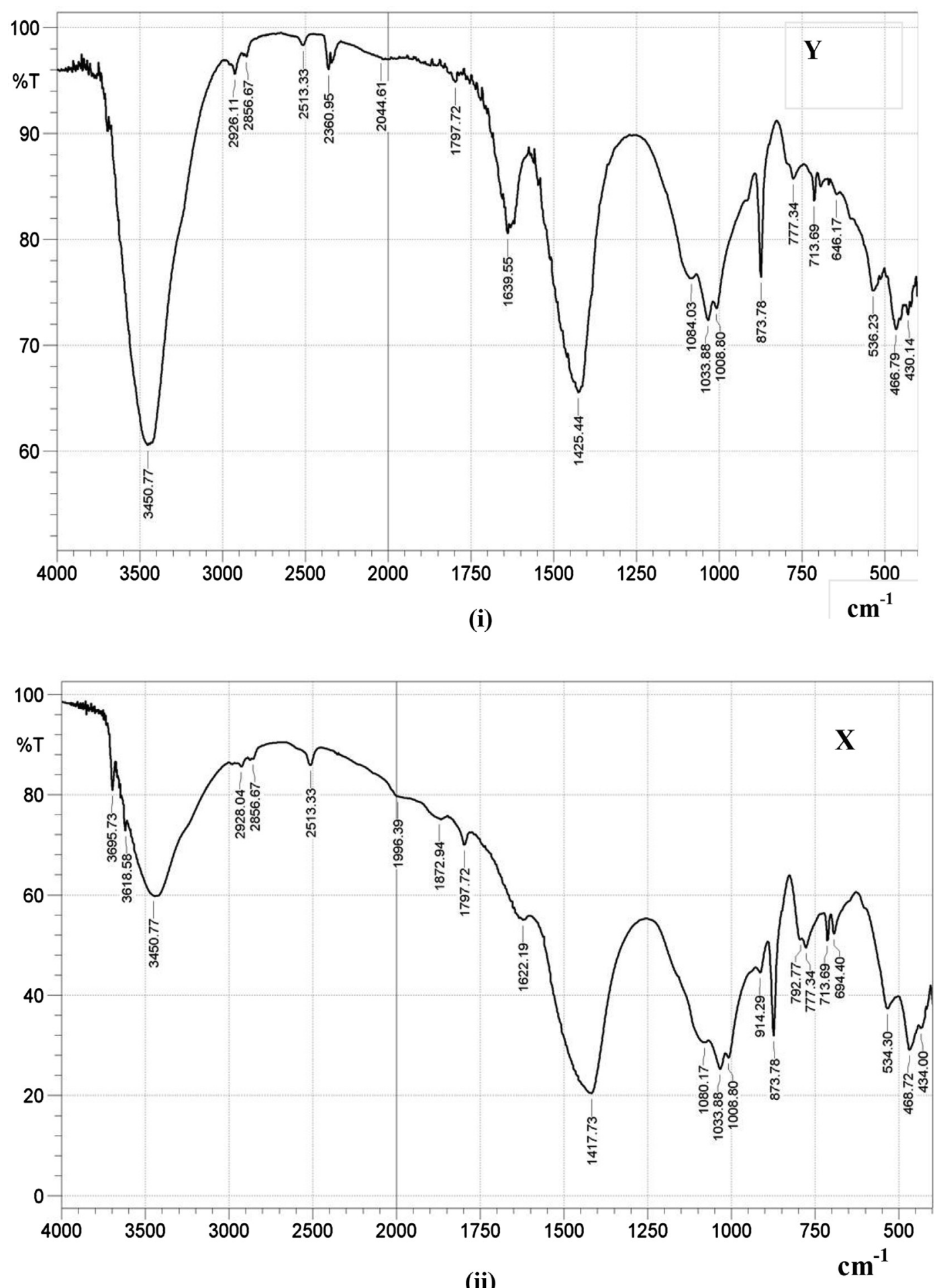

Fig. 8. FTIR graphs of (i) Y, (ii) X, (iii) W and (iv) V.

the comminingling of the pozzolanic - hydration products and polymerization reactions in the cement composite. EDS revealed that $\mathrm{C} / \mathrm{O}$ ratios are within the range of minimum level depicting reduction of cellulose and hemicellulose of the $\mathrm{BF}$ while $\mathrm{Ca} / \mathrm{Si}$ ratio was important to the formation of gels of $\mathrm{C}-\mathrm{S}-\mathrm{H}$ responsible for strength development. The optimum performance of mix V $(10 \%$ $\mathrm{WBA}+1.5 \% \mathrm{BF}+0.3 \% \mathrm{SBR}$ polymer) over the others is because the $\mathrm{C}-\mathrm{S}-\mathrm{H}$ content increased with decreasing $\mathrm{Ca} / \mathrm{Si}$ ratio and therefore the proportion of the C-S-H gel is highest at this lowest level of $\mathrm{Ca} / \mathrm{SiO}$ ratio. FTIR analysis showed that very little variations occurred in the spectra of the bands considered except for disappearance of $694.40 \mathrm{~cm}^{-1}$ and $2044.61 \mathrm{~cm}^{-1}$ bands. These are representatives of losses of the $\mathrm{C}-\mathrm{OH}$ bending and $\mathrm{C}-\mathrm{H}$ vibration bands with low intensities because of the alkaline environment of the cement hydration products. The thermal conductivity showed that the least value belongs to mix $\mathrm{V}$ with the least cement replacement (10\% WBA) while the highest TC was obtained from composition with highest cement replacement (25\% WBA). In summary, the developed fiber reinforced cement composites would provide excellent thermal, mechanical and microstructural 

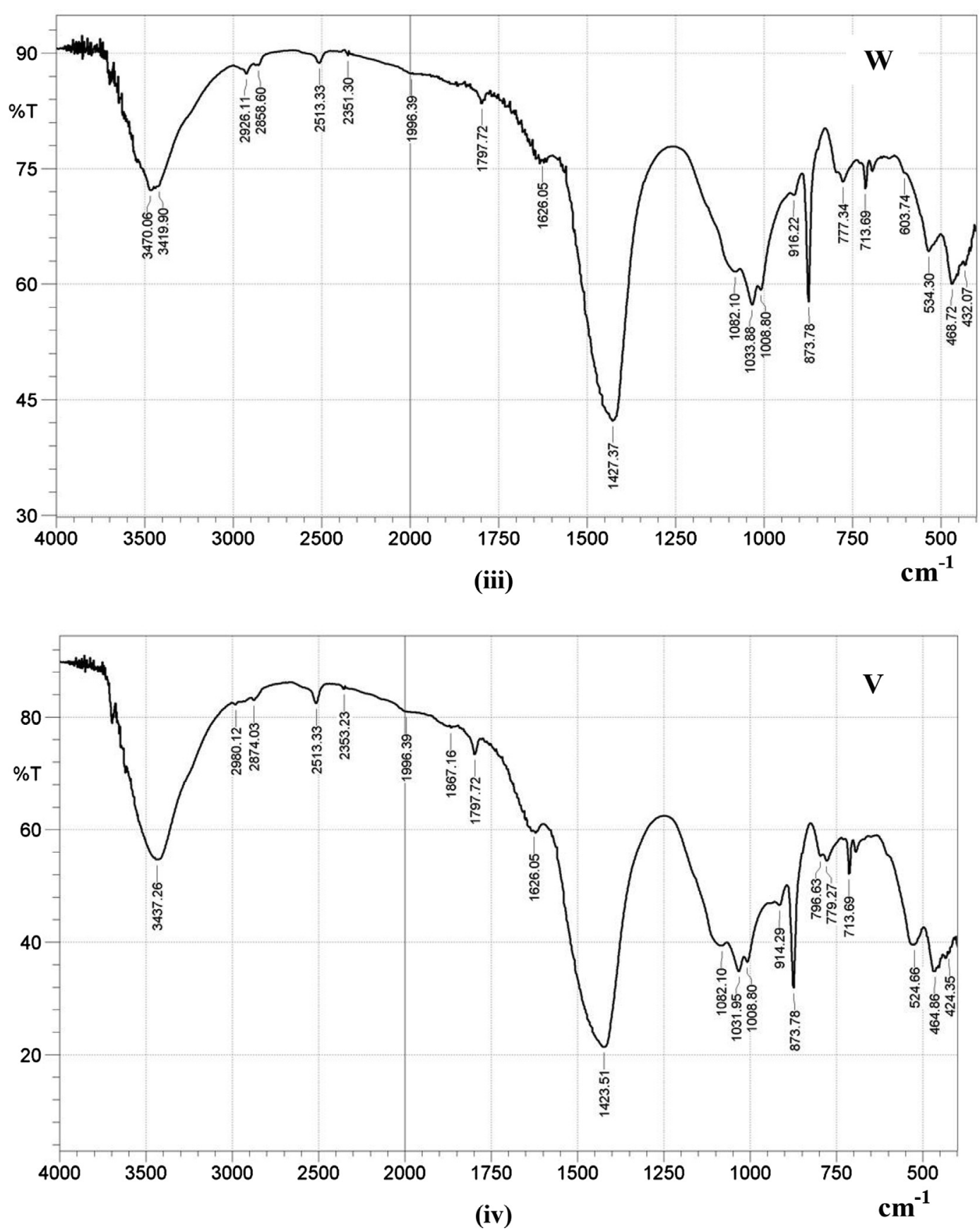

Fig. 8 (continued)

Table 4

FTIR transmittance peaks for cement composites.

\begin{tabular}{|c|c|c|c|c|c|}
\hline \multirow{2}{*}{$\frac{\text { Mixes }}{V}$} & \multicolumn{5}{|c|}{ Wavenumbers $\left(\mathrm{cm}^{-1}\right)$} \\
\hline & 3437.26 & 1626.05 & 1423.51 & 1031.95 & 464.86 \\
\hline W & 3470.06 & 1626.05 & 1427.37 & 1033.88 & 468.72 \\
\hline$X$ & 3450.77 & 1622.19 & 1417.73 & 1033.88 & 468.72 \\
\hline Y & 3450.77 & 1639.55 & 1425.44 & 1033.88 & 466.79 \\
\hline
\end{tabular}

properties if used as a construction material. Some of its possible applications are for cladding, ceiling boards, wall plaster, roofing slates, temporary shelters in emergency situations, affordable housings, decorative concrete, slabs and non-pressure pipes.

\section{CRediT authorship contribution statement}

Akinyemi Banjo Ayobami: Conceptualization, Methodology, Data curation, Writing - original draft, Visualization, Investigation, 
Table 5

Thermal conductivity of cement composites.

\begin{tabular}{ll}
\hline Compositions & Thermal Conductivity $(\mathrm{W} / \mathrm{mK})$ \\
\hline W & 0.627 \\
V & 0.620 \\
Y & 0.628 \\
X & 0.624 \\
Concrete & 1.91 \\
\hline
\end{tabular}

\section{Supervision, Writing - review \& editing. Chunping Dai: Writing - review \& editing.}

\section{Declaration of Competing Interest}

The authors declare that they have no known competing financial interests or personal relationships that could have appeared to influence the work reported in this paper.

\section{References}

[1] F.O. Obi, B.O. Ugwuishiwu, J.N. Nwakaire, Agricultural waste concept, generation, utilization and management, Nigerian J. Technol. 35 (4) (2016) 957-964.

[2] N. Venkateshwaran, A. Elayaperumal, M.S. Jagatheeshwaran, Effect of fiber length and fiber content on mechanical properties of banana fiber/epoxy composite, J. Reinf. Plast. Compos. 30 (2011) 16-21.

[3] P. Arias, The World Banana Economy, 1985-2002 (No. 1), Food \& Agriculture Org, 2003.

[4] B.A. Akinyemi, C.E. Okonkwo, E.A. Alhassan, M. Ajiboye, Durability and strength properties of particle boards from polystyrene-wood wastes, J. Mater. Cycles Waste Manage. 21 (6) (2019) 1541-1549.

[5] B. Akinyemi, T. Omoniyi, Properties of latex polymer modified mortars reinforced with waste bamboo fibers from construction waste, Buildings 8 (11) (2018) 149

[6] B.A. Akinyemi, A. Bamidele, E. Joel, Response of coir fibre reinforced cement composites to water repellent chemical additive and microwave accelerated curing, Cellulose 26 (8) (2019) 4987-4999.

[7] G. Ramakrishna, T. Sundararajan, Impact strength of a few natural fibre reinforced cement mortar slabs: a comparative study, Cem. Concr. Compos. 27 (5) (2005) 547-553.

[8] R.S.P. Coutts, Air-cured banana-fibre-reinforced cement cornposites, Cem. Concr. Compos. 16 (1994) 1-6.

[9] R.S.P. Coutts, Banana fibres as reinforcement for building products, J. Mater. Sci. Lett. 9 (10) (1990) 1235-1236.

[10] M. Mostafa, N. Uddin, Effect of banana fibers on the compressive and flexural strength of compressed earth blocks, Buildings 5 (2015) 282-296.

[11] S. Chakraborty, S.P. Kundu, A. Roy, B. Adhikari, S.B. Majumder, Polymer modified jute fibre as reinforcing agent controlling the physical and mechanical characteristics of cement mortar, Constr. Build. Mater. 49 (2013) 214-222.

[12] N. Coreido, M.N. Belgacem, I.C. Torres, J.C.V.P. Moura, Chemical composition and pulping of banana pseudo-stems, Ind. Crops Prod. 19 (2004) 147-154.

[13] M. Bishop, A.R. Barron, Cement hydration inhibition with sucrose, tartaric acid and lignosulfonate: analytical and spectroscopic study, Ind. Eng. Chem. Res. 45 (21) (2006) 7042-7049.

[14] T. Ramos, A.M. Matos, J. Sousa-Coutinho, Mortar with wood waste ash: mechanical strength carbonation resistance and ASR expansion, Constr. Build. Mater. 49 (2013) 343-351.

[15] M. da Luz Garcia, J. Sousa-Coutinho, Strength and durability of cement with forest waste bottom ash, Constr. Build. Mater. 41 (2013) 897-910.

[16] C.B. Cheah, M. Ramli, The implementation of wood waste ash as a partial cement replacement material in the production of structural grade concrete and mortar: an overview, Resour. Conserv. Recycl. 55 (7) (2011) 669-685.

[17] R. Rajamma, R.J. Ball, L.A. Tarelho, G.C. Allen, J.A. Labrincha, V.M. Ferreira, Characterisation and use of biomass fly ash in cement-based materials, J. Hazard. Mater. 172 (2-3) (2009) 1049-1060.

[18] A.U. Elinwa, S.P. Ejeh, A.M. Mamuda, Assessing of the fresh concrete properties of self-compacting concrete containing sawdust ash, Constr. Build. Mater. 22 (6) (2008) 1178-1182.

[19] S. Wang, L. Baxter, Comprehensive study of biomass fly ash in concrete: strength, microscopy, kinetics and durability, Fuel Process. Technol. 88 (1112) (2007) 1165-1170.

[20] A. Parghi, M.S. Alam, Physical and mechanical properties of cementitious composites containing recycled glass powder (RGP) and styrene butadiene rubber (SBR), Constr. Build. Mater. 104 (2016) 34-43.

[21] B.W. Jo, S. Chakraborty, K.W. Yoon, A hypothetical model based on effectiveness of combined alkali and polymer latex modified jute fibre in controlling the setting and hydration behaviour of cement, Constr. Build Mater. 68 (2014) 1-9.
[22] M. Nazerian, E. Gozali, M.D. Ghalehno, The influence of wood extractives and additives on the hydration kinetics of cement paste and cement-bonded particleboard, J. Appl. Sci. 11 (12) (2011) 2186-2192.

[23] E.Y. Okino, M.R. De Souza, M.A. Santana, M.V. da S Alves, M.E. de Sousa, D.E. Teixeira, Cement-bonded wood particleboard with a mixture of eucalypt and rubberwood, Cem. Concr. Compos. 26 (6) (2004) 729-734.

[24] American Standard for Testing and Materials (1994), Standard Specification for Coal Fly Ash and Raw or Calcined Natural Pozzolan for Use in Concrete, ASTM C 618-94.

[25] M.D. Yahaya, Physico-chemical classification of Nigerian cement, Assumption Univ. J. Technol. 12 (2009) 164-174.

[26] Akeem A. Raheem, Blessing O. Orogbade, Characteristics of blended cements produced from selected hardwood ashes, FUOYE J. Eng. Technol. 3 (1) (2018) $1-6$.

[27] B.A. Akinyemi, T.E. Omoniyi, O. Micheal, Prospects of coir fibre as reinforcement in termite mound clay bricks, Acta Technol. Agric. (2016) 5762.

[28] B.A. Akinyemi, T.E. Omoniyi, Engineering properties of acrylic emulsion polymer modified bamboo reinforced cement bonded composites, Eng. Struct. Technol. 9 (3) (2017) 126-132.

[29] ASTM D1037 (2012). Standard test methods for evaluating properties of woodbase fibre and particle panel materials.

[30] British Standards Institute. BS EN 12390-6: 2009: testing hardened concrete Part 6: tensile splitting strength of test specimens; 2009.

[31] T. Log, S.E. Gustafsson, Transient plane source (TPS) technique for measuring thermal transport properties of building materials, Fire Mater. 19 (1) (1995) 43-49.

[32] M. Barbuta, R. Bucur, A.A. Serbanoiu, S. Scutarasu, A. Burlacu, Combined effect of fly ash and fibers on properties of cement concrete, Procedia Eng. 181 (2017) 280-284.

[33] B. Ali, L.A. Qureshi, Combined effect of fly ash and glass fibers on mechanical performance of concrete, NED Univ. J. Res. 15 (3) (2018) 91-100.

[34] P.R.D. Silva, J.D. Brito, Fresh-state properties of self-compacting mortar and concrete with combined use of limestone filler and fly ash, Mater. Res. 18 (5) (2015) 1097-1108.

[35] F.M. Wegian, A. Alanki, A. Alotaibi, Influence of fly ash on behavior of fibres reinforced concrete structures, J. Appl. Sci. 11 (17) (2011) 3185-3191.

[36] B.R. Phanikumar, A. Sofi, Effect of pond ash and steel fibre on engineering properties of concrete, Ain Shams Eng. J. 7 (1) (2016) 89-99.

[37] E. Sakai, J. Sugita, Composite mechanism of polymer modified cement, Cem. Concr. Res. 25 (1) (1995) 127-135.

[38] G. Li, X. Zhao, C. Rong, Z. Wang, Properties of polymer modified steel fiberreinforced cement concretes, Constr. Build. Mater. 24 (7) (2010) 1201-1206.

[39] F.F. Udoeyo, P.U. Dashibil, Sawdust ash as concrete material, J. Mater. Civ. Eng. 14 (2) (2002) 173-176

[40] N. Sgriccia, M.C. Hawley, M. Misra, Characterization of natural fiber surfaces and natural fiber composites, Compos. A Appl. Sci. Manuf. 39 (10) (2008) 1632-1637.

[41] G.H.D. Tonoli, S.F. Santos, H. Savastano Jr, S. Delvasto, R.M. de Gutiérrez, M.D. M.L. de Murphy, Effects of natural weathering on microstructure and mineral composition of cementitious roofing tiles reinforced with fique fibre, Cem. Concr. Compos. 33 (2) (2011) 225-232.

[42] R.D. Toledo Filho, K. Scrivener, G.L. England, K. Ghavami, Durability of alkalisensitive sisal and coconut fibres in cement mortar composites, Cem. Concr. Compos. 22 (2) (2000) 127-143.

[43] A. Petrella, D. Spasiano, S. Liuzzi, U. Ayr, P. Cosma, V. Rizzi, R. Di Mundo, Use of cellulose fibers from wheat straw for sustainable cement mortars, J. Sustain. Cem.-Based Mater. 8 (3) (2019) 161-179.

[44] V. Fedorov, A. Mestnikov. Influence of cellulose fibers on structure and properties of fiber reinforced foam concrete. In MATEC Web of Conferences (Vol. 143, p. 02008). EDP Sciences, (2018).

[45] W. Kunther, S. Ferreiro, J. Skibsted, Influence of the $\mathrm{Ca} / \mathrm{Si}$ ratio on the compressive strength of cementitious calcium-silicate-hydrate binders, J. Mater. Chem. A 5 (33) (2017) 17401-17412.

[46] E.J. da Silva, M.L. Marques, F.G. Velasco, C.F. Junior, F.M. Luzardo, M.M. Tashima, A new treatment for coconut fibers to improve the properties of cement-based composites-combined effect of natural latex/pozzolanic materials, Sustain. Mater.Technol. 12 (2017) 44-51.

[47] J. Plank, M. Gretz, Study on the interaction between anionic and cationic latex particles and Portland cement, Colloids Surf., A 330 (2-3) (2008) 227233.

[48] L. Carabba, S. Manzi, M. Bignozzi, Superplasticizer addition to carbon fly ash geopolymers activated at room temperature, Materials 9 (7) (2016) 586.

[49] B. Belhadj, M. Bederina, Z. Makhloufi, R.M. Dheilly, N. Montrelay, M. Quéneudec, Contribution to the development of a sand concrete lightened by the addition of barley straws, Constr. Build. Mater. 113 (2016) 513-522.

[50] R. Demirboğa, Thermal conductivity and compressive strength of concrete incorporation with mineral admixtures, Build. Environ. 42 (7) (2007) $2467-2471$.

[51] X. Fu, D.D.L. Chung, Effect of admixtures on the thermal and thermomechanical behavior of cement paste, ACI Mater. J. 96 (4) (1999) 455-461.

[52] C. Becchio, S.P. Corgnati, A. Kindinis, S. Pagliolico, Improving environmental sustainability of concrete products: investigation on MWC thermal and mechanical properties, Energy Build. 41 (11) (2009) 1127-1134. 